Václav Sebera*, Miguel Redón-Santafé, Martin Brabec, David Děcký, Petr Čermák, Jan Tippner and Jaromír Milch

\title{
Thermally modified (TM) beech wood: compression properties, fracture toughness and cohesive law in mode II obtained from the three-point end-notched flexure (3ENF) test
}

https://doi.org/10.1515/hf-2018-0188

Received August 29, 2018; accepted January 28, 2019; previously published online March 9, 2019

Abstract: The fracture properties of thermally modified beech (Fagus sylvatica) wood (TMW) at $180^{\circ}$ and $200^{\circ} \mathrm{C}$ were evaluated in mode II using the three-point end-notched flexure (3ENF) scheme assisted by threedimensional (3D) stereovision equipment for obtaining displacements and strains. The compliance-based beam method (CBBM) provided the strain energy release rates $\left(G_{I I}\right)$ of TMW and cohesive laws for both native wood (W) and TMW. Based on the CBBM and equivalent crack length approach (ECLA), $G_{I I}$ was obtained directly from the forcedeflection data. The thermal modification (TM) process reduced the compressive strength by $4.4 \%$ and increased the compressive elastic modulus by $38.3 \%$, whereas $G_{I I}$ was reduced substantially by $40.8 \%$ and $67.9 \%$ at $\mathrm{TM}_{180^{\circ} \mathrm{C}}$ and $\mathrm{TM}_{200^{\circ} \mathrm{C}}$, respectively. TM also increased wood brittleness that was visible on the displacement slip reduction. The resulting mean cohesive models can be used for numerical analyses. The fracture properties of TMW have to be taken into consideration for constructional wood application, when cyclic loading may lead to microcracking and material fatigue.

Keywords: beech, brittleness of wood, cohesive law, compliance-based beam method (CBBM), compressive elastic modulus, digital image correlation (DIC), equivalent crack length approach (ECLA), fracture, mode II,

\footnotetext{
*Corresponding author: Václav Sebera, Department of Wood Science, Faculty of Forestry and Wood Technology, Mendel University in Brno, Zemědělská 3, 61300 Brno, Czech Republic; and Innorenew CoE, Livade 6, Izola 6310, Slovenia, e-mail:vaclav.sebera@mendelu.cz,vaclav.sebera@innorenew.eu Miguel Redón-Santafé: Department of Rural and Agrifood Engineering, School of Agriculture Engineering and Environment, Universitat Politecnica de Valencia, Camino de Vera s/n, 46110 Valencia, Spain. https://orcid.org/0000-0002-4581-1590 Martin Brabec, David Děcký, Petr Čermák, Jan Tippner and Jaromír Milch: Department of Wood Science, Faculty of Forestry and Wood Technology, Mendel University in Brno, Zemědělská 3, 61300 Brno, Czech Republic
}

thermal modification, thermally modified wood (TMW), three-point end-notched flexure (3ENF)

\section{Introduction}

Thermal modification (TM) is an efficient and economical way to decrease the equilibrium moisture content (EMC) of wood. Thermally modified wood (TMW) has an improved dimensional stability and biological durability (Tjeerdsma et al. 1998; Hill 2006; Čermák et al. 2016). Nevertheless, the range of feasible applications for TMW is limited by the reduction of strength or toughness (Borrega and Kärenlampi 2008; Hughes et al. 2015), although the stiffness of TMW is not detracted or even slightly increased (Sandberg et al. 2017). The strong influence of TM on the fracture behavior of TMW was already recognized by Koehler and Pillow (1925). TMW is more brittle than the native wood $(\mathrm{W})$, which is disadvantageous under conditions of cyclic loading, multiaxial stress and stress concentration in connections. Therefore, TMW is not suited to structural applications (Widmann et al. 2012), mainly because of the inferior fracture properties. Fracture properties are commonly studied in three fundamental modes, namely mode I (tension), mode II (shear) and mode III (torsion) (Anderson 1995). Measurement of the strain energy release in mode II may be carried out using simple analytical models, superposition, models considering crack tip openings and compliance-based methods (Wang and Qiao 2004; Yoshihara 2005; Arrese et al. 2010). Models including crack propagation phenomena are most accurate because of their direct relation to energy release. This approach was successful for synthetic and woodbased composites (Matsumoto and Nairn 2009; Wang et al. 2009). Mode II fracture is often tested in bending by employing end-notched flexural tests (ENF), either in three-point (3ENF) or four-point (4ENF) schemes. Both reveal comparable and reliable data, if certain qualitative measurement conditions and sample dimensions, such as the span-to-height ratio, are met (Schuecker and Davidson 2000; Yoshihara 2001). 
Yoshihara and Ohta (2000) found that the fracture properties of wood are dependent on the ratio of the initial crack length and half span, which have to be considered in experimental designs. de Moura et al. (2006) employed a so-called equivalent crack length approach (ECLA) and incorporated it into the compliance-based beam method (CBBM). This combination was shown to be advantageous because it did not require tracking of the crack propagation, which can be conveniently derived directly from the current compliance. The ECLA applied on a pine wood was examined by Silva et al. (2006), who also developed the finite element model (FEM) of crack propagation of wood in mode II that was successfully verified by ECLA. Silva et al. (2007) successfully tested ECLA experimentally and numerically on an end-load split (ELS) scheme, when examining the fracture properties of pine wood in mode II. The ECLA applied for medium density fiberboard (MDF) shows that fracture toughness in mode II continuously increases during crack propagation (Yoshihara 2010). Because of its relative ease, the ENF in combination with ECLA is well suited for analysis of wood bonds (Xavier et al. 2011) and for the determination of cohesive zone models of a material (Silva et al. 2014; Xavier et al. 2014) or for adhesive bonds of composite materials (Fernandes et al. 2013). The cohesive laws are especially important as input data in the numerical modeling of composite materials and structures. Méité et al. (2013) employed an optimization technique within a combination of finite element (FE) simulation and digital image correlation (DIC) analysis to characterize the fracture behavior of Douglas fir (Pseudotsuga Menziesii (Mirb.), Franco) in a mixed mode. Both tools conveniently provided data that enabled the separation of mode I and mode II without considering the local elastic mechanical properties. Jamaaou et al. (2017) used a similar approach as Méité et al. (2013) to investigate the influence of mixing modes on the total fracture properties of Douglas fir $(P$. menziesii L.) loaded perpendicular $(\perp)$ to the fiber in mode I within the wedge-splitting test (WST).

Tukiainen and Hughes (2016a) demonstrated the combined effect of elevated temperature (T) and moisture content $(\mathrm{MC})$ on the fracture properties in mode I. For spruce (Picea abies L.) and birch (Betula pendula Roth), the T/MC increase resulted in lowering of the stress intensity factor and stiffness, while the energy release rate was the highest at a dry state at $50^{\circ} \mathrm{C}$. Tukiainen and Hughes (2016b) studied the same species at a cellular level by means of environmental electron scanning microscopy (ESEM) and DIC and found in case of dry wood that microcracking was the predominant mechanism of increased toughness, and in case of wet wood that both microcracking and plastic deformation took place. The fracture properties of cherry (Prunus avium L.) and walnut (Juglans regia L.) were observed by the Arcan test in modes I and II (Murata et al. 2017), and the data from mode II were found to be more questionable due to undesired crack propagation vectors.

The influence of TM on the fracture properties of wood has been seldom studied. Kutnar et al. (2008) investigated the bonding performance of wood modified by viscoelastic thermal compression (VTC) and found an increased fracture toughness $\left(\mathrm{G}_{\text {IIc }}\right)$ compared to control samples despite low adhesive penetration. Majano-Majano et al. (2012) studied the fracture properties of TM beech (Fagus sylvatica L.) and TM ash (Fraxinus excelsior L.) in mode I. Up to $86 \%$ reduction in the fracture energy for beech at $230^{\circ} \mathrm{C}$ and a $60 \%$ reduction in the stress intensity factor were seen, while the stiffness was not changed. Tukiainen and Hughes (2016c) studied the fracture properties of spruce (P. abies L.) loaded in mode I at two temperatures in air-dried and fully saturated MCs. The fracture properties decreased as a function of TM severity. The fracture energy and stress intensity factors decreased significantly in the anatomical planes tangential-radial (TR) and radial-tangential (RT). A larger difference in fracture energy between the anatomical directions was observed at higher temperatures. Again, the stiffness was nearly unchanged or even improved. The quoted studies provide a good basis for further investigation of the fracture properties of TMW, which are of special importance for construction wood submitted to shear stresses.

The intention of the present study was to provide more insight into the fracture properties of $\mathrm{TMW}_{180^{\circ} \mathrm{C}}$ and $\mathrm{TMW}_{200^{\circ} \mathrm{C}}($ European beech) in mode II. Compression tests (CTs) were performed parallel to the fiber (CTP $)$ to provide basic data about the material. Moreover, $3 \mathrm{ENF}$ tests were performed to obtain the strain energy release rate $\left(G_{I I}\right)$ of non-modified wood (W, control) and TMW samples. In focus was the influence of TM on the fracture properties of European beech. A cohesive model was developed for W and TMW based on optical data.

\section{Materials and methods}

TM of European beech wood (F. sylvatica L.) was carried out at the two temperature levels leading to $\mathrm{TMW}_{180^{\circ} \mathrm{C}}$ and $\mathrm{TMW}_{200^{\circ} \mathrm{C}}$. The samples were conditioned and submitted to compression and the 3ENF test. The latter was accompanied by a stereoscopic system to obtain optical data about the displacement slip around the crack tip. This approach enabled the creation of a cohesive law for all samples. 


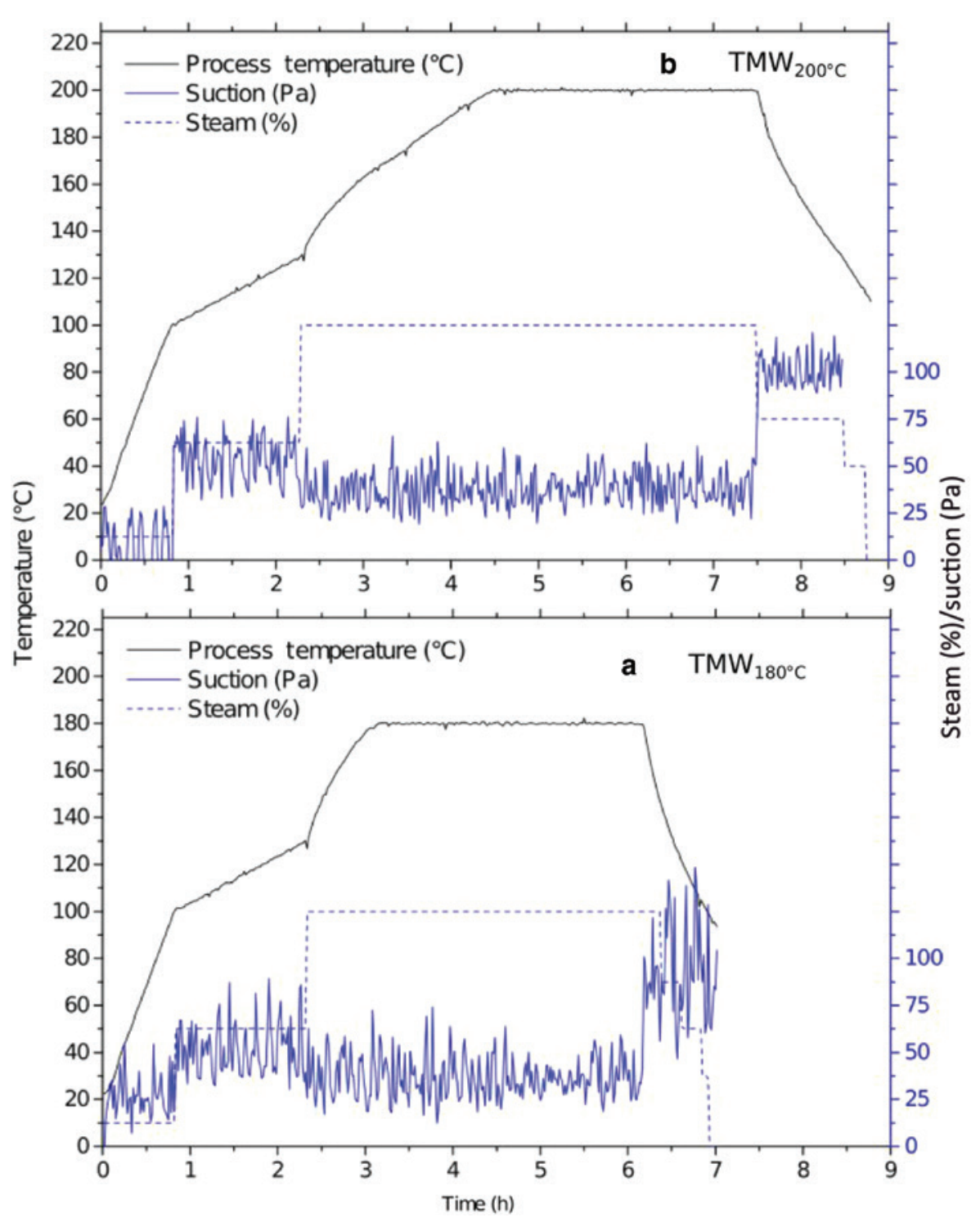

Figure 1: Technological parameters of the process to obtain thermally modified wood (TMW). Parameter for producing TMW (a) at $180^{\circ} \mathrm{C}$ and (b) at $200^{\circ} \mathrm{C}$.

Thermal modification: $\mathrm{TMW}_{180^{\circ} \mathrm{C}}$ and $\mathrm{TMW}_{200^{\circ} \mathrm{C}}$ were applied in a small-scale laboratory chamber under atmospheric pressure and superheated steam. The $\mathrm{T}_{\max }$ was maintained for $3 \mathrm{~h}$. Figure 1a,b shows the schedule of the TM throughout a period of 7-9 h. Before and after TM, all specimens were conditioned at $20^{\circ} \mathrm{C}$ and $65 \%$ relative humidity $(\mathrm{RH})$ until the EMC was reached.

Test specimens: Test specimens were cut from a defect-free board that was obtained from an $\approx 85$-year-old European beech by cutting with standard band and circular saws. Ten compression specimens were prepared for each treatment group (W, $\mathrm{TMW}_{180^{\circ} \mathrm{C}}$ and $\mathrm{TMW}_{200^{\circ} \mathrm{C}}$ ) with dimensions of $20 \times 20 \times 30 \mathrm{~mm}^{3}$ and with perfect parallel grains. For the 3ENF test, 19 specimens (Figure 2) were prepared with dimensions of $20 \times 20 \times 500 \mathrm{~mm}^{3}$ according to Yoshihara (2001) as purely orthotropic blocks and with the necessary span-to-height ratio to induce stable crack propagation and insignificant plastic deformation due to contact with testing grips. An artificial crack of length of $\approx 162 \mathrm{~mm}$ was introduced in the longitudinal (L) direction at the end of the specimen across the whole width of the specimen. The crack was oriented in the longitudinal-radial (LR) anatomical plane and was cut out into specimens with an electric wire saw after the TM process. All the specimens were weighed and dimensionally measured after and before TM, so the density could be calculated. The density of the specimens for 3ENF tests was calculated before the artificial crack was introduced.

Physical testing: Before all testing, the specimens were conditioned at $20^{\circ} \mathrm{C}$ and $65 \% \mathrm{RH}$ until the EMC was reached. Compression tests parallel to the fiber $\left(\mathrm{CT}_{\|}\right)$followed the Czech national standards ČSN 490111 and ČSN 490110 and were carried out to examine the effect of TM processing on the compressive strength $(\sigma)$ and modulus of elasticity (MOE). The information from $\mathrm{CT}_{\|}$served as a basis for further interpretation of results from the strain energy measurement in mode II. 


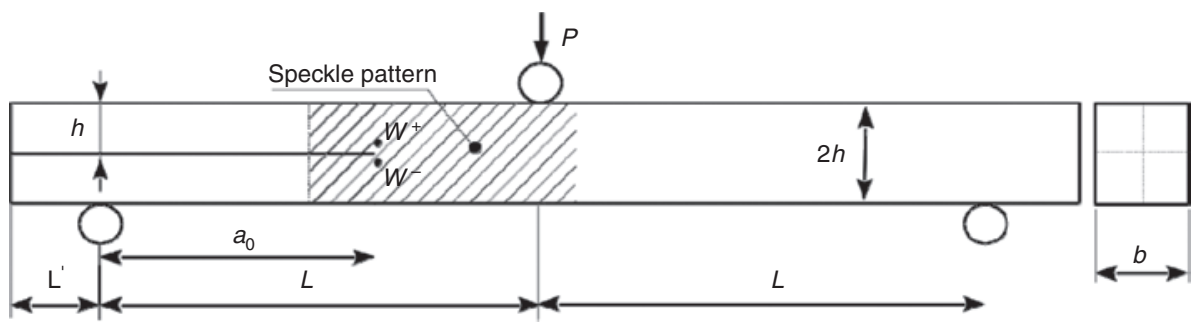

Figure 2: Scheme of sample geometry for the three-point end-notched flexure test with marked Aol for subsequent DIC analysis, and two points $\left(w^{+}, w^{-}\right)$for obtaining the displacement slip; $L=230 \mathrm{~mm}, L^{\prime}=20 \mathrm{~mm}, a_{0}=162 \mathrm{~mm}, b=20 \mathrm{~mm}, h=20 \mathrm{~mm}$.

3ENF tests were performed on a universal testing machine (UTM) Zwick Z050/TH 3A (Ulm, Germany) equipped with a 50-kN load cell. The 3ENF provided force-deflection data for further evaluation of fracture properties. Before testing, a Teflon paper was inserted into the crack to reduce friction above and below the induced crack. Also, before testing, a stochastic black-and-white speckle pattern was applied to the area of interest (AoI) within the specimens for subsequent calculation by DIC (Figure 2).

All 3ENF tests were recorded at a $2-\mathrm{Hz}$ acquisition rate by means of an optical stereovision system consisting of two 5MPx CCD cameras AVT Stingray Copper F-504B (Allied Vision, Stadtroda, Germany) equipped with Pentax C2514-M lenses focusing on one side of the AoI. The optical system was synchronized with the UTM and had a conversion factor (physical resolution) of $14 \mathrm{px} \mathrm{mm}^{-1}$. The images were further processed using three-dimensional (3D)-DIC software Vic-3D version 2010 (Correlated Solutions Inc., Irmo, SC, USA) to measure the full-field displacements and to compute the strains over the AoI. A subset size of $45 \times 45 \mathrm{px}^{2}$ and a step size of $5 \mathrm{px}$ were applied. Postprocessing of the DIC results provided the displacement slip $(w)$ that was obtained from two points at the introduced crack tip, one above and one below the assumed neutral axis (Figure 2). The displacement slip was calculated using $w_{I I}=\left\|w^{+}-w^{-}\right\|$, where $w^{+}$is for the upper component and $w^{-}$is for the lower component.

Calculation of the strain energy release rate: The theoretical derivation of $G_{I I}$ by $3 \mathrm{ENF}$ and equivalent crack length $\left(a_{\text {eqv }}\right)$ was described by Yoshihara (2010) and Fernandes et al. (2013). The fundamental calculation steps for the specimen's compliance (C) based on the beam theory including a shear effect are as follows:

$$
C=\frac{3 a_{\mathrm{eq}}^{3}+2 L^{3}}{12 E_{f} I}+\frac{3 L}{5 G_{\mathrm{LR}} A}
$$

where $G_{\mathrm{LR}}$ is the shear modulus [Pa], $A$ is the cross-section $(2 \mathrm{hb})\left[\mathrm{m}^{2}\right]$, $I$ is the second moment of area $\left[\mathrm{m}^{4}\right], E_{f}$ is the flexural modulus [Pa], $a_{\text {eqv }}=a+\Delta a_{\mathrm{FPZ}}$ where $\Delta a_{\mathrm{FPZ}}$ is the crack length correction for the fracture process zone (FPZ) effect $[\mathrm{m}]$. The mechanical responses were processed using CBBM in the calculation of $G_{I I}$ and stress. $E_{f}$ of each specimen can be estimated from the initial crack length $a_{0}$ and initial compliance $\left(C_{0}\right)$ :

$$
E_{f}=\frac{3 a_{0}^{3}+2 L^{3}}{12 I}+\left(C_{0}-\frac{3 L}{5 G_{\mathrm{LR}} A}\right)^{-1}
$$

During crack propagation, the equivalent crack length $\left(\mathrm{ECL}=a_{\text {eqv }}\right)$ can be obtained directly as:

$$
a_{\text {eqv }}=a+\Delta a_{\mathrm{FPZ}}=\left[\frac{C_{\text {corr }}}{C_{0 \text { corr }}} a_{0}^{3}+\frac{2}{3}\left(\frac{C_{\text {corr }}}{C_{0 \text { corr }}}-1\right) L^{3}\right]^{1 / 3}
$$

with

$$
C_{\text {corr }}=C-\frac{3 L}{5 G_{\mathrm{LR}} A} \text { and } C_{0 \text { corr }}=C_{0}-\frac{3 L}{5 G_{\mathrm{LR}} A}
$$

where $C_{\text {corr }}$ is the corrected compliance $\left[\mathrm{m} \cdot \mathrm{N}^{-1}\right], C$ is the current compliance $\left[\mathrm{m} \cdot \mathrm{N}^{-1}\right]$, and $C_{0 c}$ and $C_{0}$ are the initial corrected compliance $\left[\mathrm{m} \cdot \mathrm{N}^{-1}\right]$ and initial compliance $\left[\mathrm{m} \cdot \mathrm{N}^{-1}\right]$, respectively. This procedure does not require crack length monitoring during the test and leads to the direct derivation of $G_{I I}$ using the Irwin-Kies equation:

$$
G_{I I}=\frac{P^{2}}{2 B} \frac{d C}{d a}
$$

when Equation 5 is combined with Equation 1, it leads to a final expression of $G_{I I}$ :

$$
G_{I I}=\frac{9 P^{2} a_{\mathrm{eqv}}^{2}}{16 b^{2} h^{3} E_{f}}
$$

The main advantage of the present data reduction scheme is that the R-curve, i.e. $G_{I I}=f\left(a_{\text {eqv }}\right)$, can be obtained solely from the force-deflection curve. To obtain the $G_{I I}-w_{I I}$ curve, the procedure shown by Xavier et al. (2014) was followed. To derive the cohesive law, the $G_{I I}-w_{I I}$ curve was truncated at the beginning of the steadystate crack propagation (i.e. at maximal force). The truncated $G_{I I}-w_{I I}$ curve was then differentiated. For this purpose, a continuous logistic function $Q(t)$ (Equation 7) was used to approximate the data points in the reconstruction of the fracture cohesive law. The logistic fit $(Q)$ searched for the parameters $t, R$ and $\alpha$ with the lowest residuals according to the following:

$$
Q=\frac{Q_{\text {inf }}}{1+e^{-\alpha(t-R)}}
$$

where $Q$ is the logistic function, $Q_{\text {inf }}$ is the curve maximum, $t$ is the time, $R$ is the symmetric inflection point and $\alpha$ is the time decay constant. Once the continuous function of $G_{I I}\left(w_{I I}\right)$ was obtained, the $G_{I I}$ was differentiated as follows:

$$
\sigma_{I I}=\frac{\partial G_{I I}}{\partial w_{I I}}
$$

where $\sigma_{I I}$ is the stress $[\mathrm{Pa}]$ and $w_{I I}$ is the displacement slip [m]. To examine the differences between the studied group's mean values, one-way analysis of variance (ANOVA) tests were used, assuming a level of significance of 0.05. Postprocessing, statistical analyses and other calculations were performed using Matlab 2014b (Mathworks Inc., Natick, MA, USA). 


\section{Results and discussion}

\section{Compression tests}

The compressive strength $(\sigma)$ and the elastic modulus (E) obtained directly from CTs (all groups in Figure 3 without $*$ ) do not solely account for the effect of TM because these are influenced by varying MCs. The TMs influenced the hygroscopicity of wood and led to different EMC values: the mean MCs of $\mathrm{W}, \mathrm{TMW}_{180^{\circ} \mathrm{C}}$ and $\mathrm{TMW}_{200^{\circ} \mathrm{C}}$ were 9.74, 4.15 and 3.10\%, respectively. For comparison, both $\sigma$ and MOE were adjusted to a frequently used MC level of $12 \%$ by means of the following equations:

$$
\sigma^{*}=\sigma[1+\alpha(\mathrm{MC}-12)] \text { and } E^{*}=E[1+\alpha(\mathrm{MC}-12)],
$$
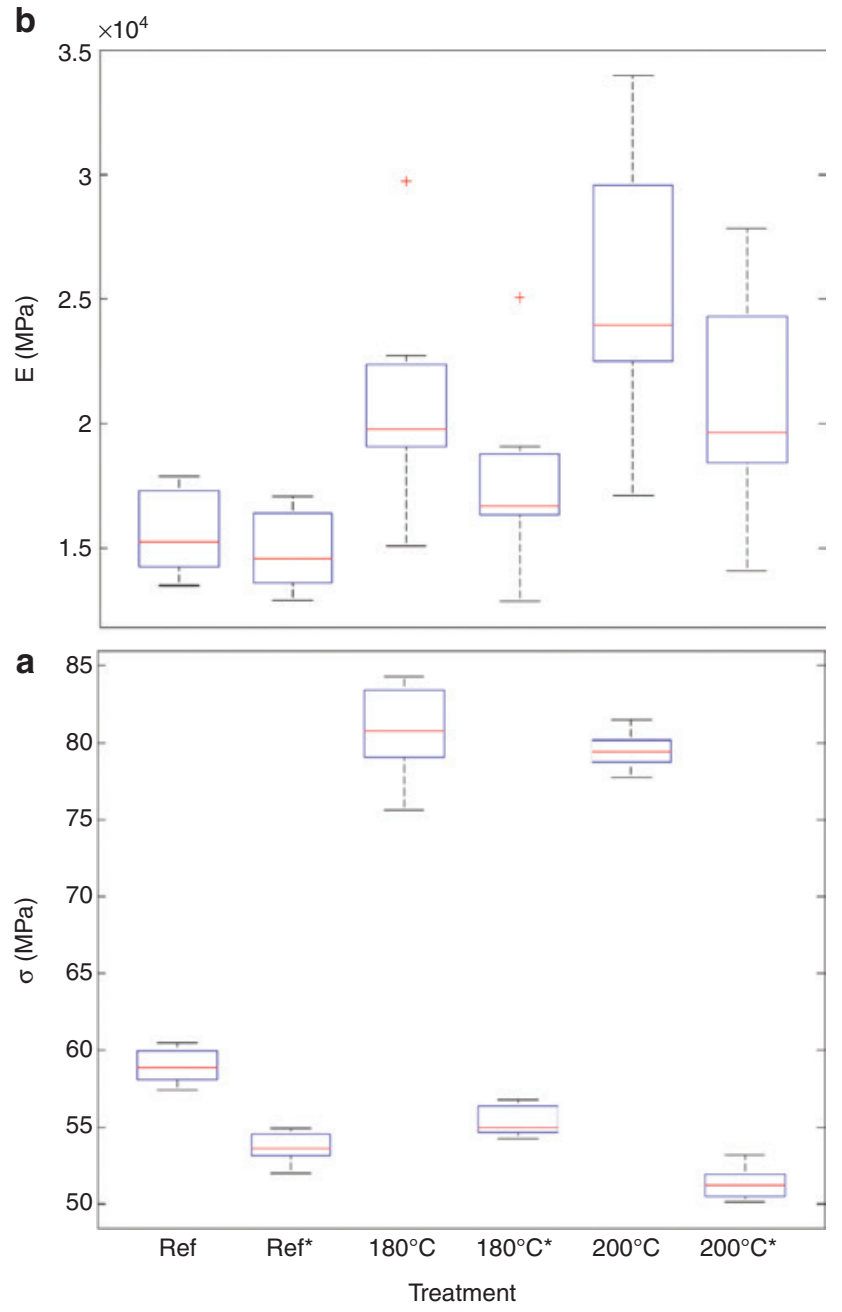

Figure 3: Results from compression tests.

(a) Compression strength parallel to fiber - measured and adjusted to $12 \%$ MC (denoted with *), (b) Compressive elastic modulus parallel to fiber - measured and adjusted to $12 \%$ MC (denoted with *). Box plot middle line expresses the median of the group. where $\alpha=0.04$ is for $\sigma$, and $\alpha=0.02$ is for $E$. These coefficients are from the Czech national standards ČSN 49 0110 and ČSN 49 0111. The adjusted results are depicted in Figure 3 as groups denoted with an asterisk (*). The coefficients for untreated wood (W) were reliable, but in case of TMWs they were more questionable and limited. Nonetheless, they are useful for comparative purposes, if the material properties are measured at the same MC level.

A one-way ANOVA test for the CS $(\sigma)$ of unadjusted $M C s$ revealed significant differences between $W$ and TMWs $(\alpha=0.05)$. The mean $\sigma$ of TMWs did not significantly differ from each other. However, after the adjustment of $\sigma$ to $\sigma^{*}$ to account for MC, all groups differed significantly (Figure 3). Before adjustment, the mean CS of $\mathrm{TMW}_{180^{\circ} \mathrm{C}}$ and $\mathrm{TMW}_{200^{\circ} \mathrm{C}}$ were 36.7 and 34.7\% higher (relative difference) compared to $\mathrm{W}$, respectively. After the adjustments, the mean $\sigma$ of $\mathrm{TMW}_{180^{\circ} \mathrm{C}}$ and $\mathrm{TMW}_{200^{\circ}}$ groups were 3.1 and $4.44 \%$ higher than the W group, respectively. The mean $E$ values for the adjusted $\mathrm{W}, \mathrm{TMW}_{180^{\circ} \mathrm{C}}$ and $\mathrm{TMW}_{200^{\circ} \mathrm{C}}$ were $53.7 \pm 0.92$, $55.3 \pm 0.90$ and $51.3 \pm 98 \mathrm{MPa}$, respectively. The reduced $\sigma$ between the two TMWs were less than that between $\mathrm{W}$ and $\mathrm{TMW}_{180^{\circ} \mathrm{C}}$. For the unadjusted $E$, the one-way ANOVA revealed significant differences between all groups. After the adjustment of $E$ to the same MC level, only W and $\mathrm{TMW}_{200^{\circ} \mathrm{C}}$ groups differed significantly in their mean values. Figure 3 shows that the adjustment of $E$ lowered the differences amongst all groups, but in absolute values the TMWs showed higher $E$ than the W group. The mean $E^{\prime \prime}$ for W, $\mathrm{TMW}_{180^{\circ} \mathrm{C}}$ and $\mathrm{TMW}_{200^{\circ} \mathrm{C}}$ groups were $14923 \pm 1525$, $17180 \pm 3300$ and $20640 \pm 4284 \mathrm{MPa}$, respectively, while only the differences between $\mathrm{W}$ and $\mathrm{TMW}_{200^{\circ} \mathrm{C}}$ groups were significant.

\section{End-notched flexural tests}

The analytical calculation of $G_{I I}$ follows the ECLA for the determination of the resistance curve (R-curve) that was explicitly derived from the experimental load-displacement $(P-u)$ curves (Figure 4). Whereas the $\sigma$ and $E$ obtained from the CT increased without adjustments to EMC, the maximal force $\left(P_{\max }\right)$ and deflection at maximal force $\left(u_{\max }\right)$ substantially decreased at the 3ENF tests. The relative decrement of the mean $P_{\max }$ with respect to the $\mathrm{W}$ control group was $32.9 \%$ for the $\mathrm{TMW}_{180^{\circ} \mathrm{C}}$ group and $51.6 \%$ for the $\mathrm{TMW}_{200^{\circ} \mathrm{C}}$ group. Such a significant decrement means that the shear strength (SS) is more affected by TM than the compression strength (CS), where the reduction was only $4.44 \%$ for $\mathrm{TMW}_{200^{\circ} \mathrm{c}}$. The one-way ANOVA test revealed that all three groups' means differed significantly $(\alpha=0.05)$ regarding both the unadjusted measures $P_{\max }$ and $u_{\max }$. For 


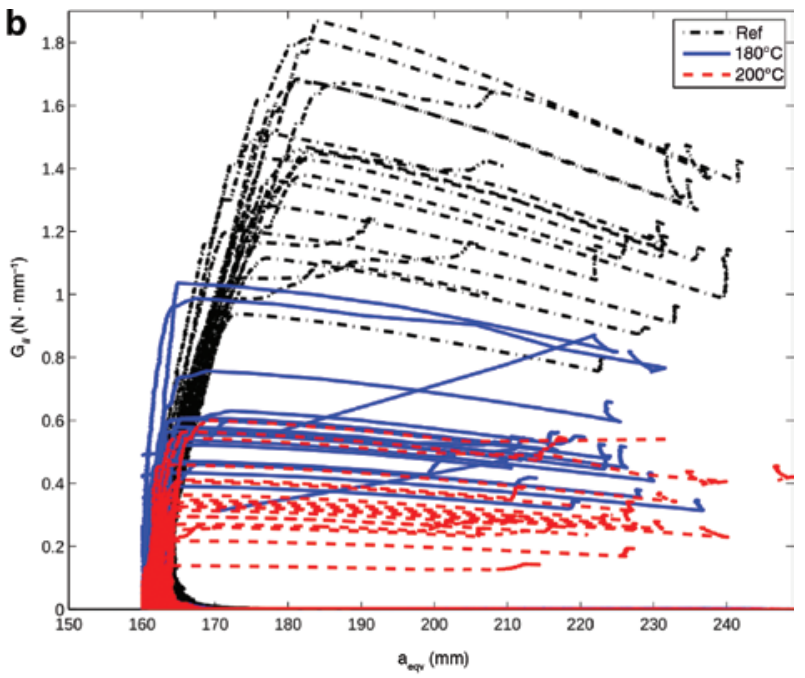

a

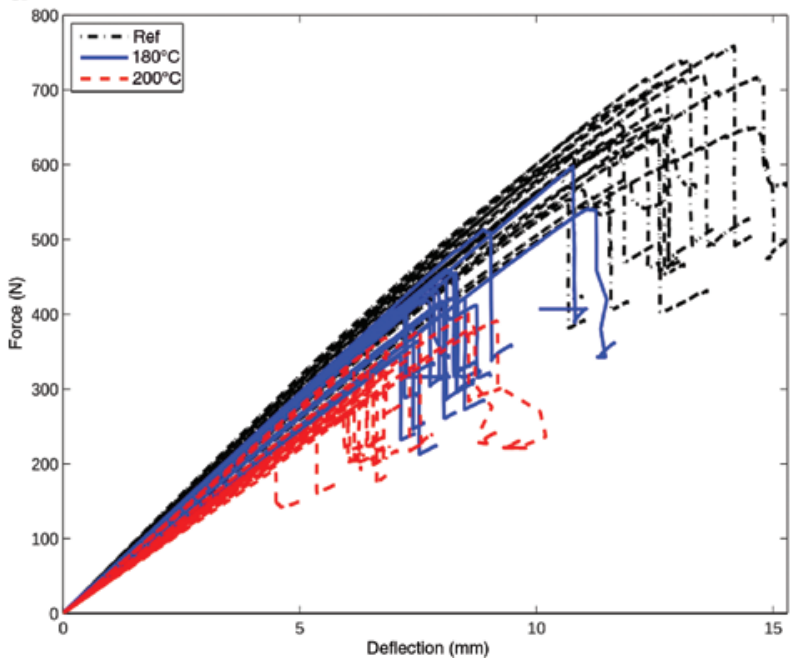

Figure 4: Results from the 3ENF tests.

(a) Force-deflection diagrams for non-treated wood (black dash-anddot line), treated at $180^{\circ} \mathrm{C}$ (blue solid line) and treated at $200^{\circ} \mathrm{C}$ (red dashed line), (b) the strain energy release rate $\left(G_{\|}\right)$dependent on the equivalent crack length $\left(a_{\text {eqv }}\right)$ of non-treated wood, wood treated at $180^{\circ} \mathrm{C}$ and wood treated at $200^{\circ} \mathrm{C}$.

these specific properties, the adjustment to EMC could not be carried out because no data were available concerning the influence of MC on $P_{\max }$ and $u_{\max }$ for 3ENF tests and their associated $\alpha$ coefficients. Nevertheless, it can be concluded that the maximal forces and deflection data were much lower for TMW, while the opposite is true for compressive $\sigma$ and MOE.

Optical measurements were carried out using the 3D-DIC software, which provided displacements in three directions ( $\mathrm{x}, \mathrm{y}$ and $\mathrm{z}$ ), strains in two directions ( $\varepsilon_{\mathrm{xx}}$ and $\left.\varepsilon_{y y}\right)$ and the shear strain $\left(\varepsilon_{x y}\right)$. The calculated horizontal displacement field $(u)$, which provided data for further analysis, especially the data of $w^{+}$and $w^{-}$, is shown in
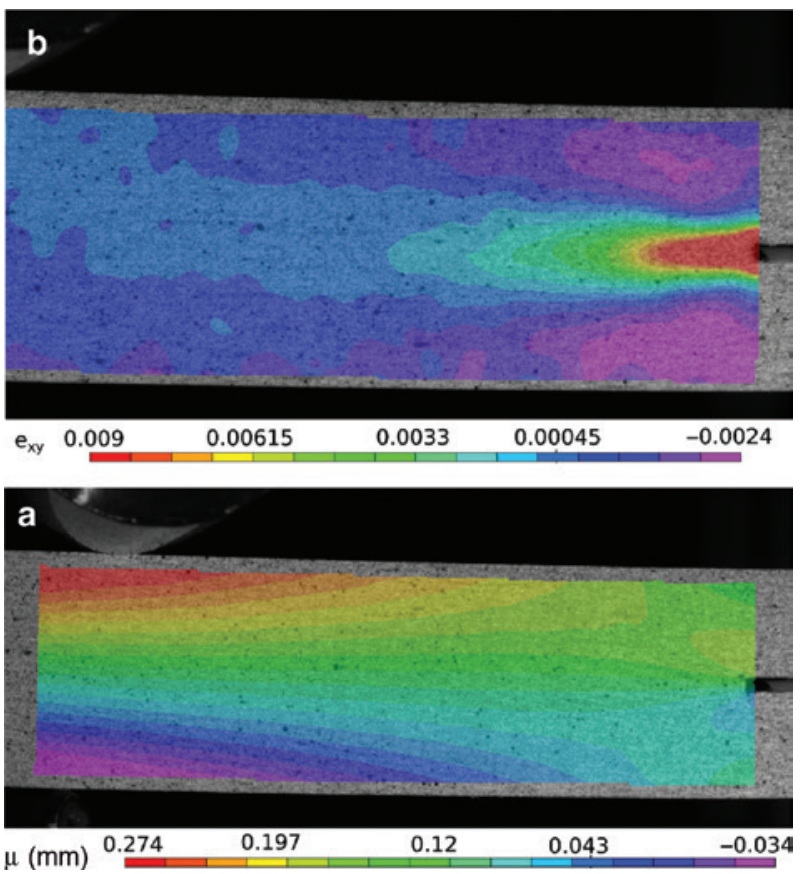

Figure 5: Outputs from the DIC computation.

(a) Horizontal displacement $(u)$ at the proportional limit for the sample from Ref group, (b) shear strain $\left(\varepsilon_{x y}\right)$ at the crack tip at the proportional limit for the sample from Ref group.

Figure 5a. In Figure 5b, it is visible that the highest shear strain occurred at the crack tip as desired for mode II testing. The displacement and strain plots from all other specimens (not shown) looked similar to those seen in Figure 5.

Looking at Figure $4 \mathrm{~b}$ depicting $G_{I I}$ vs. the computed ECL $\left(a_{\text {eqv }}\right)$, it can be concluded that $G_{I I \max }$ also substantially reduced in the course of TM. The mean values of $G_{I I \max }$ for $\mathrm{W}, \mathrm{TMW}_{180^{\circ} \mathrm{C}}$ and $\mathrm{TMW}_{200^{\circ} \mathrm{C}}$ were 1.41, 0.657 and $0.356 \mathrm{~N} \mathrm{~mm}^{-1}$, respectively. Compared to the $\mathrm{W}$ group, the mean $G_{I I \max }$ was reduced by 53.4 and $74.8 \%$ for the $\mathrm{TMW}_{180^{\circ} \mathrm{C}}$ and $\mathrm{TMW}_{200^{\circ} \mathrm{C}}$ groups, respectively. MajanoMajano et al. (2012) found a similar reduction (57 and $76 \%)$ in mode I fracture energies at the same anatomical plane, final TM temperatures and at a very similar MC level. Accordingly, the fracture energy reduction due to TM seems to be similar in mode I and mode II. This reduction can also be seen in Figure 4a, which shows that both elastic and plastic parts of toughness were reduced substantially. Because shear is the predominant loading scheme in mode II, the reduction of $G_{I I}$ on a molecular level may be likely attributed to changes in the ligninhemicelluloses complex that produces a cohesive matrix. These changes most likely consist of cleavage to the polymeric structure and a weakening of the chemical bonds. 
The cellulose chains are less affected by the shear load. According to the ANOVA results, all three groups had significantly different mean values of $G_{I I \max }$, which could not be adjusted for EMC because of the non-availability the $\alpha$ coefficient for $G_{I I}$. However, some authors calculated approximative $\alpha$ values for equalizing to the same MC (Reiterer and Tschegg 2002; Majano-Majano et al. 2012). Majano-Majano et al. (2012) provided data concerning the influence of $\mathrm{MC}$ on the energy release rate in mode I $\left(G_{\mathrm{I}}\right)$. Based on their findings, the following $\alpha$ coefficients were applied in the present study: $\alpha_{\text {Ref }}=0.024, \alpha_{180^{\circ} \mathrm{C}}=0.0378$ and $\alpha_{200^{\circ} \mathrm{C}}=0.0374$, and the $G_{I I \max }$ data were equalized to $12 \%$ EMC by the following equation: $G_{I I \max } *=G_{I I \max }$ $[1+\alpha(12-\mathrm{w})]$. The result of the equalization is depicted in Figure 6. Obviously, the adjusted $G_{I I \max }$ for both the TMW groups increased slightly due to equalization to $12 \%$
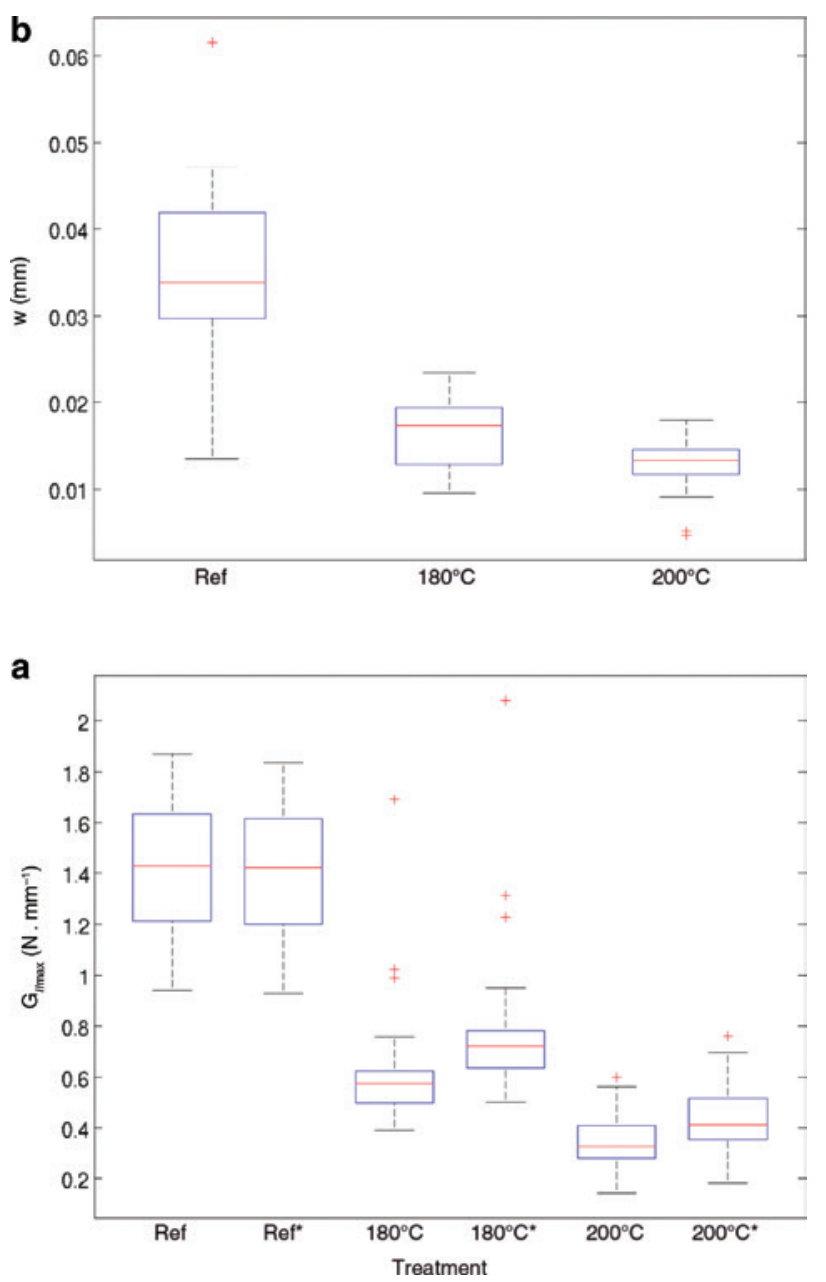

Figure 6: Fracture properties derived from 3ENF tests.

(a) The strain energy release rate for all groups, unadjusted and adjusted to $12 \%$ MC (signed with $*$ ), (b) the displacement slip $w$ at maximal $G_{l / \max }\left(w_{\max }\right)$ dependent on the treatment.
$\mathrm{MC}$, but the data were lower than that of the $\mathrm{W}$ group. The reduction of the adjusted mean $G_{I I \max }$ for $\mathrm{TMW}_{180^{\circ} \mathrm{C}}$ and $\mathrm{TMW}_{200^{\circ} \mathrm{C}}$ groups was 40.8 , and $67.9 \%$, respectively. This reduction was slightly lower than for the unadjusted groups but was still high when compared to other mechanical properties that change due to the TM treatments. It is questionable as to what degree the $\alpha$ coefficient derived from a work dealing with mode I can be used for mode II, but perhaps this approach is useful to obtain approximative values for comparative purposes as seen earlier in the case of CT analysis.

The Pearson correlation coefficients amongst the physical qualities obtained from the 3ENF tests are listed in Table 1. As visible, (i) a very high $R$ was found between the flexural modulus and density except in the $\mathrm{TMW}_{200^{\circ} \mathrm{C}}$ group; (ii) the correlation between $F_{\text {max }}$ and $G_{I I \max }$ was very high and expected as both qualities are closely related via the applied calculation process; (iii) a high negative correlation was found between $\sigma_{I I \max }$ and $w_{\text {IImax }}$, which implies that the TM process makes wood more brittle because it reaches maximal stress at lower displacement slip levels.

Results of the fit of the logistic function (Equation 7) to the curve $G_{I I}$ vs. $w_{I I}$ before steady crack propagation occurred are presented in Figure $7 \mathrm{a}$. The differentiation

Table 1: Correlation coefficients $(\mathrm{R})$ amongst the measured physical quantities within the same treatment groups $(n=19)$.

\begin{tabular}{|c|c|c|c|c|c|c|}
\hline \multirow[b]{2}{*}{ Data } & \multirow[b]{2}{*}{ Group } & \multicolumn{5}{|r|}{ Data } \\
\hline & & $\boldsymbol{F}_{\max }$ & $\boldsymbol{G}_{I / \max }$ & $w_{l / \max }$ & $\sigma_{l / \max }$ & $E_{f}$ \\
\hline \multirow[t]{3}{*}{$\rho$} & Ref & 0.53 & 0.32 & -0.068 & 0.40 & 0.87 \\
\hline & $180^{\circ} \mathrm{C}$ & 0.45 & 0.34 & -0.024 & 0.26 & 0.95 \\
\hline & $200^{\circ} \mathrm{C}$ & 0.04 & 0.075 & -0.094 & 0.23 & 0.32 \\
\hline \multirow[t]{3}{*}{$M C$} & Ref & 0.035 & -0.11 & -0.17 & 0.14 & 0.28 \\
\hline & $180^{\circ} \mathrm{C}$ & 0.51 & 0.42 & 0.27 & 0.24 & -0.23 \\
\hline & $200^{\circ} \mathrm{C}$ & 0.22 & 0.27 & 0.33 & 0.04 & -0.12 \\
\hline \multirow[t]{3}{*}{$F_{\max }$} & Ref & - & 0.90 & 0.33 & 0.22 & 0.51 \\
\hline & $180^{\circ} \mathrm{C}$ & & 0.85 & 0.39 & 0.38 & 0.36 \\
\hline & $200^{\circ} \mathrm{C}$ & & 0.95 & 0.28 & 0.40 & 0.39 \\
\hline \multirow[t]{3}{*}{$G_{I / \max }$} & Ref & $\|$ & - & 0.45 & 0.12 & 0.19 \\
\hline & $180^{\circ} \mathrm{C}$ & & & 0.27 & 0.40 & 0.22 \\
\hline & $200^{\circ} \mathrm{C}$ & & & 0.32 & 0.34 & 0.15 \\
\hline \multirow[t]{3}{*}{$\mathrm{w}_{l / \max }$} & Ref & $\|$ & $\|$ & - & -0.72 & -0.09 \\
\hline & $180^{\circ} \mathrm{C}$ & & & & -0.67 & -0.04 \\
\hline & $200^{\circ} \mathrm{C}$ & & & & -0.63 & -0.25 \\
\hline \multirow[t]{3}{*}{$\sigma_{/ / \max }$} & Ref & $\|$ & $\|$ & $\|$ & - & 0.29 \\
\hline & $180^{\circ} \mathrm{C}$ & & & & & 0.18 \\
\hline & $200^{\circ} \mathrm{C}$ & & & & & 0.48 \\
\hline
\end{tabular}

MC, Moisture content. $R^{2} \geq 0.4$ is bold. 

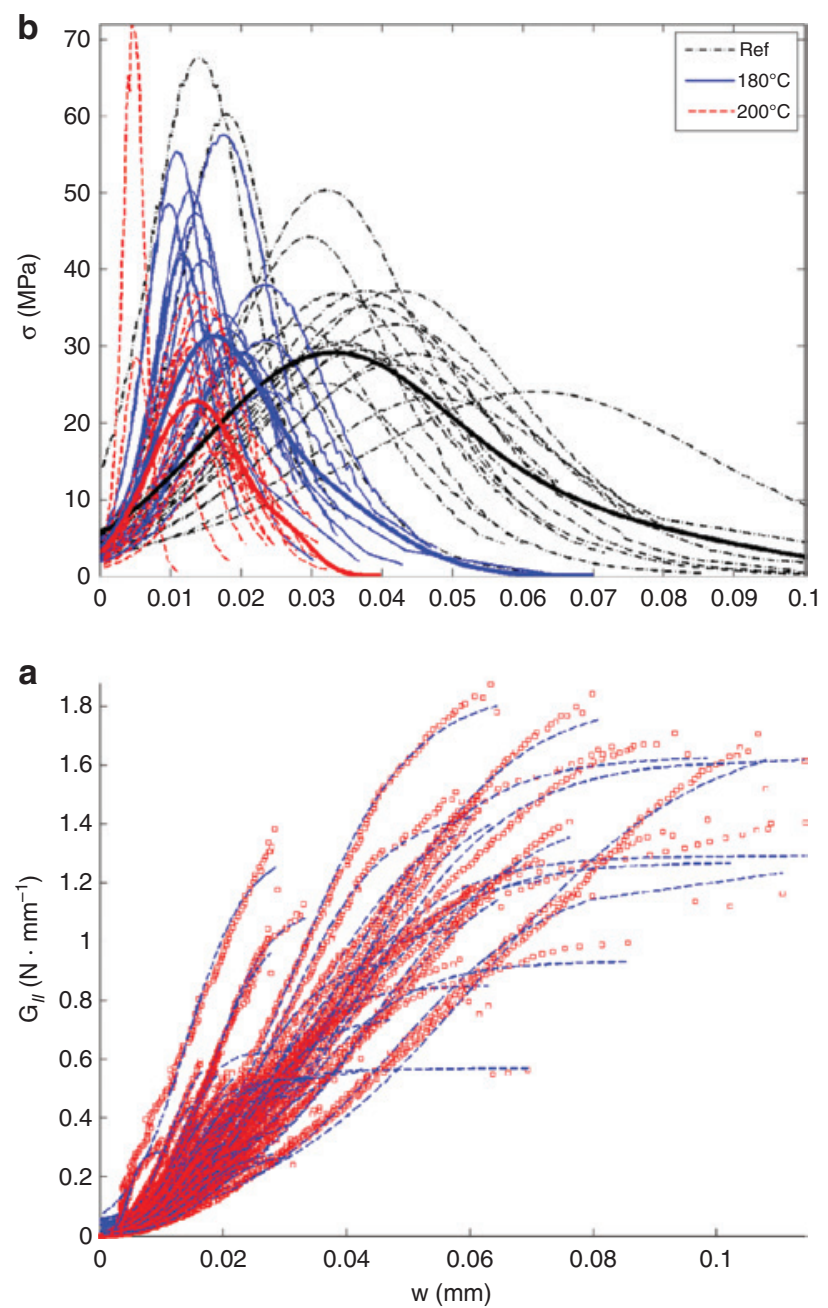

Figure 7: Derivation of cohesive law models.

(a) Fit of logistic function (blue dashed line) to experimental data (red squares), (b) stress vs. displacement slip dependent on the treatment - bold lines express fit of mean curve using the Gaussian function.

of Equation 7 led to the $\sigma_{I I}$ vs. $w_{I I}$ relationship, which expresses the cohesive law (Figure $7 \mathrm{~b}$ ). The one-way ANOVA showed that only $\mathrm{TMW}_{180^{\circ} \mathrm{C}}$ and $\mathrm{TMW}_{200^{\circ} \mathrm{C}}$ groups differ significantly in the mean values of $\sigma_{I I \max }$, whereas the $\mathrm{W}$ group did not differ from both modified groups even after removing outliers from all groups. On the other hand, the one-way ANOVA revealed statistical differences between the $\mathrm{W}$ group and both TMWs in terms of $w_{I I \max }$, which was highly correlated with the maximal stress achieved. These findings suggest that TMW is more susceptible to fracture parallel to fiber in the LR plane compared to the untreated wood.

The mean curves of the $\sigma_{I I}$ vs. $w_{I I}$ are plotted in Figure $7 \mathrm{~b}$. These mean curves were further fitted by the twoterm Gaussian model, to reach a smooth distribution of $\sigma_{I I}$
Table 2: Cohesive law for all groups in the form of the Gaussian model.

\begin{tabular}{lrrrrrrr}
\hline Group & $a_{1}$ & $a_{2}$ & $b_{1}$ & $b_{2}$ & $c_{1}$ & $c_{2}$ & $\mathbf{R}^{2}$ \\
\hline Ref & 25.23 & 7.472 & 0.03116 & 0.0617 & 0.024500 & 0.0367 & 0.996 \\
$180^{\circ} \mathrm{C}$ & 23.37 & 12.52 & 0.01481 & 0.02689 & 0.009965 & 0.0169 & 0.994 \\
$200^{\circ} \mathrm{C}$ & 22.84 & 3.432 & 0.01353 & 0.02727 & 0.009514 & 0.00486 & 0.988 \\
\hline
\end{tabular}

vs. $w_{I I}$. The fitted mean curves are depicted in Figure $7 \mathrm{~b}$ as three bold lines, representing each treatment group. The mean curves were fitted to account for varying lengths of input data. The Gaussian model with the following notation was chosen because of its suitability to fit the peaks' data:

$$
f=\sum_{i=1}^{2} a_{i} e^{\left[-\left(\frac{x-b_{i}}{c_{i}}\right)^{2}\right]}
$$

where coefficients $a_{i}, b_{i}$ and $c_{i}$, express the amplitude, centroid and peak width, respectively. A summary of these coefficients together with $\mathrm{R}^{2}$ of the fit is provided in Table 2. The fitted mean curves in Figure 7 clearly show the increased brittleness of the TMWs and a significant decrease in the maximal stress for the $\mathrm{TMW}_{200^{\circ} \mathrm{C}}$ group compared to $\mathrm{W}$ and $\mathrm{TMW}_{180^{\circ} \mathrm{C}}$.

\section{Conclusions}

TM does not essentially change the compressive strength of European beech wood parallel to the fiber $\left(\mathrm{CS}_{\|}\right)$; however, minor CS reductions (rel. difference of 4.44\%) were seen for $\mathrm{TMW}_{200^{\circ} \mathrm{C}}$. TM increased the compressive modulus of elasticity $(E)$ up to 15.1 and $38.3 \%$ for $\mathrm{TMW}_{180^{\circ} \mathrm{C}}$ and $\mathrm{TMW}_{200^{\circ} \mathrm{C}}$, respectively. TM substantially reduced the fracture performance of wood in the LR plane with increasing temperature. The reduction of the maximal energy release rate $\left(G_{I I \max }\right)$ was 40.8 and $67.9 \%$ for $\mathrm{TMW}_{180^{\circ} \mathrm{C}}$ and $\mathrm{TMW}_{200^{\circ} \mathrm{C}}$, respectively. One-way ANOVA of the displacement slip amongst all groups showed that the wood became more brittle at higher TM temperatures. Three cohesive laws for the fracture mode II were derived for $\mathrm{W}$ and TMWs in the LR plane. The Gaussian models describe well the interrelations and can be used in numerical analyses. If TMW should be applied as engineering wood, further research is needed. This holds especially true, when TM wood is used in applications submitted to cyclic mechanical loading that often leads to the fatigue of the component due to the microcracking and macrocracking in later stages of the loading. 
Author contributions: All the authors have accepted responsibility for the entire content of this submitted manuscript and approved submission.

Research funding: The authors would like to thank COST Action FP1407 (Funder Id: https://dx.doi. org/10.13039/501100000921), the European Commission for funding the InnoRenew CoE project under the Horizon2020 Widespread-Teaming program (grant agreement \#739574), the Republic of Slovenia for providing support from the European Regional Development Funds, and the financial support provided by the Internal Grant Agency (IGA) of the Faculty of Forestry and Wood Technology, Mendel University in Brno (LDF_PSV_2016015).

Employment or leadership: None declared.

Honorarium: None declared.

\section{References}

Anderson, T. Fracture Mechanics: Fundamentals and Applications. 2nd ed. CRC, Boca Raton, FL, 1995.

Arrese, A., Carbajal, N., Vargas, G., Mujika, F. (2010) A new method of determining mode II R-curve by the End-Notched Flexure test. E. Fr. Mech. 77:51-70.

Borrega, M., Kärenlampi, P.P. (2008) Mechanisches Verhalten von Wärmebehandeltem Fichtenholz (Picea abies) bei Konstanter Holz- und Luftfeuchte [Mechanical behavior of heat-treated spruce (Picea abies) wood at constant moisture content and ambient humidity]. Holz Roh Werk. 66:63-69.

Čermák, P., Vahtikari, K., Rautkari, L., Laine, K., Horáček, P., Baar, J. (2016) The effect of wetting cycles on moisture behaviour of thermally modified Scots pine (Pinus sylvestris L.) wood. J. Mater. Sci. 51:1504-1511.

de Moura, M.F.S.F., Silva, M.A.L., de Morais, A.B., Morais, J.J.L. (2006) Equivalent crack based mode II fracture characterization of wood. Eng. Fract. Mech. 73:978-993.

Fernandes, R.M.R.P., Chousal, J.A.G., de Moura, M.F.S.F., Xavier, J. (2013) Determination of cohesive laws of composite bonded joints under mode II loading. Composites: Part B 52:269-274.

Hill, C. Wood Modification: Chemical, Thermal and Other Processes, Wiley Series. In: Renewable Resources. John Wiley \& Sons, Hoboken, USA, 2006.

Hughes, M., Hill, C., Pfriem, A. (2015) The toughness of hygrothermally modified wood: COST Action FP0904 2010-2014: Thermo-hydro-mechanical wood behavior and processing. Holzforschung 69:851-862.

Jamaaou, A., Pop, O., Dubois, F., Costa, G. (2017) Wedge Splitting Test on Douglas genotypes using an integrated mixed-mode approach. Theor. Appl. Fract. Mec. 91:44-51.

Kutnar, A., Kamke, F., Nairn, J., Sernek, M. (2008) Mode II fracture behavior of bonded viscoelastic thermal compressed wood. Wood Fiber Sci. 40:362-373.

Majano-Majano, A., Hughes, M., Fernandez-Cabo, J.L. (2012) The fracture toughness and properties of thermally modified beech and ash at different moisture contents. Wood Sci. Technol. 46:5-21.
Matsumoto, N., Nairn, J.A. (2009) The fracture toughness of medium density fiberboard (MDF) including the effects of fiber bridging and crack-plane interference. Eng. Fract. Mech. 76:2748-2757.

Méité, M., Dubois, F., Pop, O., Absi, J. (2013) Mixed mode fracture properties characterization for wood by digital images correlation and finite element method coupling. Eng. Fract. Mech. 105:86-100.

Murata, K., Bachtiar, E.V., Niemz, P. (2017) Determination of mode I and mode II fracture toughness of walnut and cherry in TR and RT crack propagation system by the Arcan test. Holzforschung 71:985-990.

Sandberg, D., Kutnar, A., Mantanis, G. (2017) Wood modification technologies - a review. IForest 10:895-908.

Schuecker, C., Davidson, B.D. (2000) Evaluation of the accuracy of the four-point bend end-notched flexure test for mode II delamination toughness determination. Compos. Sci. Technol. 60:2137-2146

Silva, M.A.L., de Moura, M.F.S.F., Morais, J.J.L. (2006) Numerical analysis of the ENF test for mode II wood fracture. Compos. Part A-Appl. S. 37:1334-1344.

Silva, M.A.L., Morais, J.J.L., de Moura, M.F.S.F., Lousada, J.L. (2007) Mode II wood fracture characterization using the ELS test. Eng. Fract. Mech. 74:2133-2147.

Silva, F.G.A., Morais, J.J.L., Dourado, N., Xavier, J., Pereira, F.A.M., De Moura, M.F.S.F. (2014) Determination of cohesive laws in wood bonded joints under mode II loading using the ENF test. Int. J. Adhes. Adhes. 51:54-61.

Tjeerdsma, B.F., Boonstra, M., Pizzi, A., Tekely, P., Militz, H. (1998) Characterisation of thermally modified wood: molecular reasons for wood performance improvement. Holz Roh-Werkst 56:149-153.

Tukiainen, P., Hughes, M. (2016a) The effect of elevated temperature and high moisture content on the fracture behaviour of thermally modified spruce. J. Mat. Sci. 51:1437-1444.

Tukiainen, P., Hughes, M. (2016b) The cellular level mode I fracture behaviour of spruce and birch in the RT crack propagation system. Holzforschung 70:157-165.

Tukiainen, P., Hughes, M. (2016c) The effect of temperature and moisture content on the fracture behaviour of spruce and birch. Holzforschung 70:369-376.

Wang, J., Qiao, P. (2004) Novel beam analysis of end notched flexure specimen for mode-II fracture. Eng. Fract. Mech. 71:219-231.

Wang, W.X., Nakata, M., Takao, Y., Matsubara, T. (2009) Experimental investigation on test methods for mode II interlaminar fracture testing of carbon fiber reinforced composites. Compos. Part A-Appl. 40:1447-1455.

Widmann, R., Fernandez-Cabo, J.L., Steiger, R. (2012) Mechanical properties of thermally modified beech timber for structural purposes. Eur. J. Wood Wood Prod. 70:775-784.

Xavier, J., Morais, J., Dourado, N., De Moura, M.F.S.F. (2011) Measurement of mode I and mode II fracture properties of woodbonded joints. J. Adhes. Sci. Technol. 25:2881-2895.

Xavier, J., Oliveira, M., Morais, J.J.L., De Moura, M.F.S.F. (2014) Determining mode II cohesive law of Pinus pinaster by combining the end-notched flexure test with digital image correlation. Constr. Build. Mater. 71:109-115.

Yoshihara, H. (2001) Influence of span/depth ratio on the measurement of mode II fracture toughness of wood by end-notched flexure test. J. Wood Sci. 47:8-12. 
Yoshihara, H. (2005) Mode II initiation fracture toughness analysis for wood obtained by 3-ENF test. Compos. Sci. Technol. 65:2198-2207.

Yoshihara, H. (2010) Mode I and mode II initiation fracture toughness and resistance curve of medium density fiberboard measured by double cantilever beam and three-point bend end-notched flexure tests. Eng. Fract. Mech. 77:2537-2549. Yoshihara, H., Ohta, M. (2000) Measurement of mode II fracture toughness of wood by the end-notched flexure test. J. Wood Sci. 46:273-278. 